\title{
Pregnancy History, Hypertension, and Cognitive Impairment in Postmenopausal Women
}

\author{
Kathleen B. Miller ${ }^{1}$ - Virginia M. Miller ${ }^{2,3} \cdot$ Jill N. Barnes ${ }^{1}$ \\ Published online: 18 November 2019 \\ (C) The Author(s) 2019
}

\begin{abstract}
Purpose of Review Risks for developing cardiovascular disease and cognitive decline increase with age. In women, these risks may be influenced by pregnancy history. This review provides an integrated evaluation of associations of pregnancy history with hypertension, brain atrophy, and cognitive decline in postmenopausal women.

Recent Findings Atrophy in the occipital lobes of the brain was evident in women who had current hypertension and a history of preeclampsia. Deficits in visual memory in women with a history of preeclampsia are consistent with these brain structural changes. The blood velocity response to chemical and sympathoexcitatory stimuli were altered in women with a history of preeclampsia linking impairments in cerebrovascular regulation to the structural and functional changes in the brain.

Summary Having a history of preeclampsia should require close monitoring of blood pressure and initiation of anti-hypertensive treatment in perimenopausal women. Mechanisms by which preeclampsia affects cerebrovascular structure and function require additional study.
\end{abstract}

Keywords Alzheimer's disease $\cdot$ Gray matter $\cdot$ Menopause $\cdot$ Neurovascular control $\cdot$ Preeclampsia $\cdot$ White matter hyperintensities

\section{Introduction}

Studies have repeatedly demonstrated an association between hypertension and Alzheimer's disease and other dementias [1-3]. Sex difference in the incidence of hypertension between men and women has been reported for over 50 years $[4,5]$; however, previous studies have not considered associations between hypertension and Alzheimer's disease relative to sex, hormonal status, or other potential risk factors

This article is part of the Topical Collection on Secondary Hypertension: Nervous System Mechanisms

Virginia M. Miller miller.virginia@mayo.edu

1 Department of Kinesiology, University of Wisconsin-Madison, Madison, WI, USA

2 Department of Surgery, Mayo Clinic, Medical Sci Bldg 421, 200 First St SW, Rochester, MN 55905, USA

3 Department of Physiology and Biomedical Engineering, Mayo Clinic, Medical Sci Bldg 421, 200 First St SW, Rochester, MN 55905, USA that might differ between men and women [6]. Young women have lower blood pressure and less prevalence of hypertension compared with young men [5]. Yet, the risk for developing hypertension increases in women at menopause. Along with menopause, there are female-specific conditions that may augment risk for both hypertension and cognitive decline. For example, the abrupt loss of ovarian hormones following bilateral oophorectomy before the age of 45 years increases the incidence of cardiovascular disease and neurological conditions [7••]. In addition to surgical menopause, pregnancy is considered a stress test for cardiovascular health which has implications for structural and functional changes in the brain. Hypertensive pregnancy disorders, such as preeclampsia, increase the risk for hypertension later in life by 3 to 4 times that of women who had a normotensive pregnancy $[8,9]$. Importantly, many studies of women with a history of preeclampsia only evaluate women a few years postpartum and do not consider the combined effect of menopause and pregnancy history on cardiovascular and brain health. Thus, the purpose of this review is to provide an integrated evaluation of associations of pregnancy history, specifically a history of preeclampsia, with development of hypertension, brain atrophy, and cognitive decline in postmenopausal women. 


\section{Hypertension, Cognitive Decline, and Alzheimer's Disease}

A 2016 scientific statement from the American Heart Association identified strong evidence for the detrimental impact of midlife hypertension on late-life cognitive function, thus highlighting the importance of considering hypertension as a major contributor to accelerated cognitive decline [10, $11 \bullet \cdot]$. The concept that hypertension influences cognition was identified as early as the 1960s when it was discovered that pilots and air traffic controllers with hypertension had reduced psychomotor speed compared with controllers without hypertension [12]. In addition, a longitudinal study published in 1971 suggested "significant intellectual loss" over a 10 -year period in hypertensive individuals that was not evident in age-matched normotensive individuals [13]. Since then, multiple other studies have provided evidence suggesting that individuals with hypertension, especially during midlife, have increased risk for cognitive decline, independent of stroke [14]. The mechanisms by which hypertension increases risk for cognitive decline are not fully understood. Neuroimaging studies in humans have identified structural brain changes normally associated with cognitive decline in hypertensive individuals such as reduced gray matter brain volume coupled with increased volume of white matter hyperintensities $(\mathrm{WMH})[15,16]$. Importantly, brain atrophy in hypertensive individuals is evident in regions typically susceptible to Alzheimer's disease pathology. In addition to structural brain changes, there are declines in function of the cerebral blood vessels in hypertensive individuals [17] including lowered cerebral blood flow [18], altered cerebral autoregulation [19], and impaired neurovascular coupling [17]. These changes link cerebrovascular function to increases in the brain's susceptibility to elevated systemic blood pressure. Hypertensive individuals also demonstrate higher levels of Alzheimer's disease related pathology compared to normotensive controls, such as reduced glucose metabolism [20], increased $\beta$-amyloid plaques [21], and neurofibrillary tangles [22], all which may be related to the aforementioned reductions in function of the cerebral blood vessels. It is possible that hypertension-induced impairments in brain structure or neurovascular dysfunction may precede development of Alzheimer's disease pathology and occur years before there are observed reductions in cognitive dysfunction [23, 24]. Therefore, managing hypertension in midlife could have subsequent cognitive effects in later-life, but these ideas are difficult to study and require a longitudinal approach. Clinical trials aimed at controlling blood pressure in order to mitigate declines in cognitive function or reduce the risk of Alzheimer's disease are ongoing with promising preliminary results $[25,26]$. Although the Systolic Blood Pressure Intervention Trial (SPRINT) did not see a reduction in probable dementia with anti-hypertensive therapy, the study likely did not extend long enough to capture changes in cognition, as the median intervention lasted only 3.3 years. Furthermore, the SPRINT trial, among others, lacks information about how sex and hormonal status may impact the effects of hypertension on cognitive function. Thus, the cognitive consequences of sex-specific conditions of hypertension, such as hypertension during pregnancy or preeclampsia, are only beginning to be understood. Future studies on hypertensive women and specifically women with a history of hypertensive pregnancy disorders are warranted.

\section{Preeclampsia}

Preeclampsia is defined as de novo hypertension and proteinuria or other evidence of significant end-organ damage after 20 -week gestation [27]. The incidence of preeclampsia is approximately $2-8 \%$ worldwide, occurring in approximately $4 \%$ of pregnancies in the USA [28]. Preeclampsia increases fetal risk, as $20 \%$ of cases result in preterm birth which can augment risk for perinatal mortality and morbidity [29]. In addition, maternal risk is also increased, as preeclampsia can develop into eclampsia (seizure) and cause severe neurological damage including death [30]. Despite blood pressure returning to normotensive levels after delivery, women with a history of preeclampsia are at a higher risk for cardiovascular disease [31], including hypertension and ischemic heart disease, and renal disease [32]. In addition, and as highlighted in this review, there are long-term effects of preeclampsia on brain structure, cerebrovascular function, and cognition.

The pathophysiology of preeclampsia is unknown. Preeclampsia is associated with the failure of the spiral arteries of the decidua and myometrium to remodel early during pregnancy subsequently reducing blood flow to the placenta [33, 34] and increasing placental oxidative stress [35]. There is evidence to suggest that the placenta then secretes antiangiogenic factors [36,37], resulting in widespread maternal vascular dysfunction [38] and elevated sympathetic nervous system activity [39, 40]. Risk factors for developing preeclampsia include insulin resistance and diabetes [relative risk (RR) 3.7], chronic hypertension (RR 5.1), obesity (RR 2.8), chronic kidney disease (RR 1.8), lupus (RR 1.8), antiphospholipid syndrome (RR 2.8), a family history of preeclampsia (2.9), and advanced maternal age (1.2) [41]. Multifetal pregnancy (RR 2.9) is also a significant risk factor for preeclampsia. In addition, a past history of preeclampsia increases the risk for preeclampsia for subsequent pregnancies 8-fold (RR 8.4) [42, 43]. Although many risk factors for preeclampsia suggest preexisting autonomic or autoimmune dysfunction, these are not obligatory for preeclampsia to develop. Thus, whether the aforementioned risk factors are causal, or pregnancy exacerbates a preexisting propensity for hypertension, is yet to be understood. 


\section{Evaluating the Long-Term Effects of Preeclampsia}

Many epidemiological studies have retrospectively addressed the effects of preeclampsia on maternal cardiovascular disease risk $[9,44]$, as well as the association between preeclampsia and risk for maternal cognitive decline [45••]. Few studies, however, have focused on the effect of hormonal changes on agingrelated pathophysiology or integrated associations between vascular function and brain pathology because such studies require long-term follow-up and continuous funding across several generations of investigators. It is possible to leverage large clinical databases to evaluate women prospectively based on pregnancy history. These databases can then be used to examine longitudinal effects of hypertensive pregnancy or preeclampsia on cardiovascular and brain health. For example, the Rochester Epidemiology Project medical records linkage system was used to identify from a larger population-based cohort, age- and parity-matched women with and without histories of preeclampsia [46••]. These women were postmenopausal with the average age of 60 years and about 35 years past the incident pregnancy. The following sections of this review will highlight some of the findings in this cohort of postmenopausal women with different pregnancy histories.

\section{Preeclampsia and Cardiovascular Function}

In the cohort of postmenopausal women identified as clinically asymptomatic for cardiovascular disease through the Rochester Epidemiology Project, the incidence of hypertension and use of anti-hypertensive medications were more frequent in women with a history of preeclampsia [46••]. Furthermore, upon computed tomographic (CT) imaging of their coronary arteries, women with a history of preeclampsia had significantly greater accumulation of calcium in the coronary arteries compared with women who had a history of a normotensive pregnancy [46••]. In addition, carotid intimamedia thickness was greater in women with a history of preeclampsia compared to those with a history of a normotensive pregnancy, indicating perhaps a more generalized risk for cardiovascular disease $[47 \cdot \bullet]$ and structural changes in large and small peripheral arteries.

In addition to the structural changes observed in the coronary and carotid arteries, it is possible that a history of preeclampsia may be associated with altered central hemodynamics. Altered central hemodynamics may not be obvious by evaluating standard clinical brachial blood pressures, as changes in the structure of the central elastic arteries may precede clinical changes in brachial blood pressure [48] and manifest as increased arterial stiffness or elevated central blood pressure. Importantly, increases in central blood pressure may be more influential than brachial blood pressure when evaluating the hemodynamic stress on target organs, especially considering the proximity of the target organs (such as the brain) to the heart [49]. Thus, even if brachial blood pressure is within a normative range, central blood pressure and arterial stiffness may be associated with vascular brain injury. In this context, fraction of WMH, a biomarker for cognitive decline $[50,51]$, associated with increasing central arterial blood pressure in postmenopausal women [52]. Women with preeclampsia have increased central arterial stiffness, which augments central blood pressure, during pregnancy [53, 54], and central arterial stiffness remains elevated during the months postpartum [55]. In women evaluated 35 years postpartum, there was an inverse relationship between central blood pressure and cognitive function scores in postmenopausal women with a history of preeclampsia but not in women with a history of a normotensive pregnancy (unpublished observations from our group). These observations suggest underlying vascular dysfunction in the large elastic arteries that may impact cerebrovascular function and ultimately cognition.

\section{Preeclampsia and Cerebrovascular Function}

The mechanisms by which hypertension, or history of preeclampsia, influences the function of the cerebral blood vessels are beginning to be explored in preclinical studies. Associated changes in the structure and function of the central elastic arteries may affect the cerebral circulation, as the central elastic arteries are responsible for dampening large pulsatile forces from myocardial contraction that can translate to the brain's microcirculation. Myogenic function of the cerebral arteries is essential for maintaining cerebral autoregulation. Cerebral autoregulation protects the brain against elevated blood pressure, which occurs during a preeclamptic pregnancy. For example, in animal models of preeclampsia, intracranial cerebral arteries [56] and hippocampal arterioles [57] do not remodel and have impaired myogenic tone [58] in response to pregnancy. The loss of autoregulation may result from dysregulation of ion channels in the cerebral parenchymal arterioles [59*0]. A consequence of impaired cerebral autoregulation during a hypertensive condition such as preeclampsia is hyperperfusion of the brain, which may increase permeability of the blood-brain barrier and cause neuroinflammation (see [60 $\left.{ }^{\circ}\right]$ for review). In this context, animal models of preeclampsia have demonstrated that hyperperfusion results in lasting damage to the cerebral vasculature and blood-brain barrier [56, 61].

In humans, cerebrovascular function can be assessed by measurable changes in cerebral blood flow in response to a stimulus (e.g., increased $\mathrm{CO}_{2}$ ). This change is defined as cerebrovascular reactivity (CVR) and is thought to reflect the function of the cerebral vessels (i.e., arteries, arterioles, capillaries) [62]. CVR is reduced in populations with cognitive impairment, supporting an association between CVR and cognitive decline [63-65]. Women with preeclampsia have lower CVR during 
pregnancy compared with women with a normotensive pregnancy $[66,67]$. In the cohort of postmenopausal women with a history of preeclampsia, CVR was lower than in women with a history of a normotensive pregnancy even 35 years after the incident pregnancy [68・•]. Reductions in CVR in women with a history of preeclampsia were associated with increased vascular activation [68・•]. In addition, these postmenopausal women with a history of preeclampsia demonstrated an augmented cerebral blood velocity response to a sympathoexcitatory stimulus compared with women with a history of a normotensive pregnancy (unpublished observations from our group). Taken together, these results suggest that a history of having preeclampsia is associated with impaired neurovascular control. It is important to consider that it is unknown if differences in central blood pressure, vascular activation, and CVR may exist among women prior to pregnancy and, if so, might represent a unique predisposing phenotype for preeclampsia. Regardless, impaired neurovascular control may cause chronic hypoperfusion leading to brain structural changes associated with cognitive decline. Alternatively, impaired neurovascular control may directly affect cognitive function due to impairments in neurovascular coupling. Future studies should continue to utilize animals and humans to evaluate how preeclampsia contributes to impairments in cerebral blood vessels, which will ultimately help elucidate the link between preeclampsia, cerebrovascular dysfunction, and cognitive decline.

\section{Preeclampsia and Brain Structure}

In addition to the evidence suggesting that a history of preeclampsia is associated with reduced cerebrovascular function, it is possible that preeclampsia also influences brain structure. Indeed, studies that have evaluated women less than 10 years postpartum suggest that a history of preeclampsia is associated with increased WMH volumes [69-71], typically associated with increased risk for accelerated cognitive decline $[50,51]$. Few studies, however, have evaluated brain structure in postmenopausal women with a history of preeclampsia. One population-based study evaluated brain volume in women decades postpartum and found that women with a history of preeclampsia had reduced gray matter volumes compared with women with a history of a normotensive pregnancy [72], even after adjustment for other cardiovascular risk factors. Taken together, these findings suggest that a history of preeclampsia has an impact on both white matter and gray matter structures that is apparent $10+$ years postpartum.

Having ongoing or current hypertension may also impact changes in gray matter volume depending on pregnancy history. In women with a history of preeclampsia and a current diagnosis of hypertension, gray matter volume was reduced compared with women with a history of preeclampsia who were normotensive and women with a history of a normotensive pregnancy [73••].
Using a voxel-based analysis, those women with a history of preeclampsia and current hypertension demonstrated gray matter atrophy in the occipital cortex compared with women with a history of preeclampsia who were normotensive [73••]. In addition, those with a history of preeclampsia and current hypertension had reduced gray matter volume in both prefrontal and sensorimotor cortices in both hemispheres compared with women who had a history of a normotensive pregnancy and were currently normotensive $[73 \bullet \bullet]$. These findings suggest that there are specific regions of the brain that may be more sensitive to injury by preeclampsia, and that brain atrophy may be exacerbated by current hypertension. The presence of WMH and evidence of brain atrophy are consistent with other biomarkers of accelerated brain aging and increased risk for cognitive decline. Future studies can identify how other neuroimaging biomarkers of $\operatorname{cog}$ nitive decline are affected by pregnancy history.

\section{Preeclampsia and Cognitive Decline}

Epidemiological evidence suggests that there is an association between a history of preeclampsia and cognitive decline [45••]; however, few studies have evaluated this idea prospectively. In a cohort of postmenopausal women with otherwise low cardiovascular risk, women with a history of preeclampsia demonstrated deficits in visual memory reflecting damage to the occipital region of the brain, consistent with findings regarding gray matter atrophy in the occipital lobe [74.*0. In addition, there was a trend for women with a history of preeclampsia to be clinically diagnosed with mild cognitive impairment more frequently than women with a history of a normotensive pregnancy [74••]. These women with a history of preeclampsia also exhibited a more diffuse range of cognitive impairment [74••]. These findings 35 years postpartum extend results from studies of women with a history of preeclampsia less than 10 years postpartum suggesting a high incidence of cognitive complaints [75-77], as well as reduced motor speed, attention, and learning and memory performance $[75,77,78]$. The findings from this cohort of postmenopausal women add to the growing body of literature identifying the detrimental impact of hypertension on cognition later in life. Because preeclampsia is a hypertensive episode with potential lasting effects on the central vasculature, cerebral vasculature, and brain structure, future studies should further investigate the impact of preeclampsia on cognitive function. In addition, future studies should evaluate how pregnancy history effects cognitive function over the life span, including during times of hormonal flux during perimenopause and into postmenopause.

\section{Conclusions}

In a prospective study of a carefully defined cohort of postmenopausal women with a history of preeclampsia and parity- 
matched women with a history of a normotensive pregnancy who had otherwise low cardiovascular risk, having a history of preeclampsia had an impact on neurovascular control and vascular anatomy characterized by increased coronary artery calcification and increased carotid intima-media thickness. Structural changes to the central arteries were reflected by increased central blood pressures that were associated with reduced cognitive testing scores only in women with a history of preeclampsia. In these postmenopausal women with a history of preeclampsia and current hypertension, CVR was reduced contributing perhaps to reduced total gray matter volumes and regional gray matter volume (Fig. 1). Furthermore, having current hypertension amplified gray matter atrophy in the occipital lobes that was consistent with deficits in visual memory in women with a history of preeclampsia. There was trend for women with history of preeclampsia to have increased incidence of clinical cognitive impairment diagnosis with a more diffuse range (i.e., multiple domains) in cognitive impairment compared with women who had a history of a normotensive pregnancy (Fig. 1).

These data add to the mounting evidence suggesting the detrimental impact of hypertension, especially during early and midlife, on cognition later in life. In 2017, the American Heart Association revised the guidelines for the diagnosis and treatment of hypertension by lowering the threshold for both systolic and diastolic blood pressures by $10 \mathrm{mmHg}$ [79]. Given that some changes in the brain structure in women, related to development of WMH, can occur with blood pressures $<140 / 90 \mathrm{mmHg}$ [52], earlier interventions for blood pressure control could reduce these unfavorable changes in brain structure. Treating hypertension at the earliest stages is critical, as little is known about how duration of untreated hypertension or duration of anti-hypertensive treatment can compound the effects on the cerebral blood vessels, neurovascular coupling, and brain structure. As preeclampsia is a hypertensive episode, and a history of preeclampsia

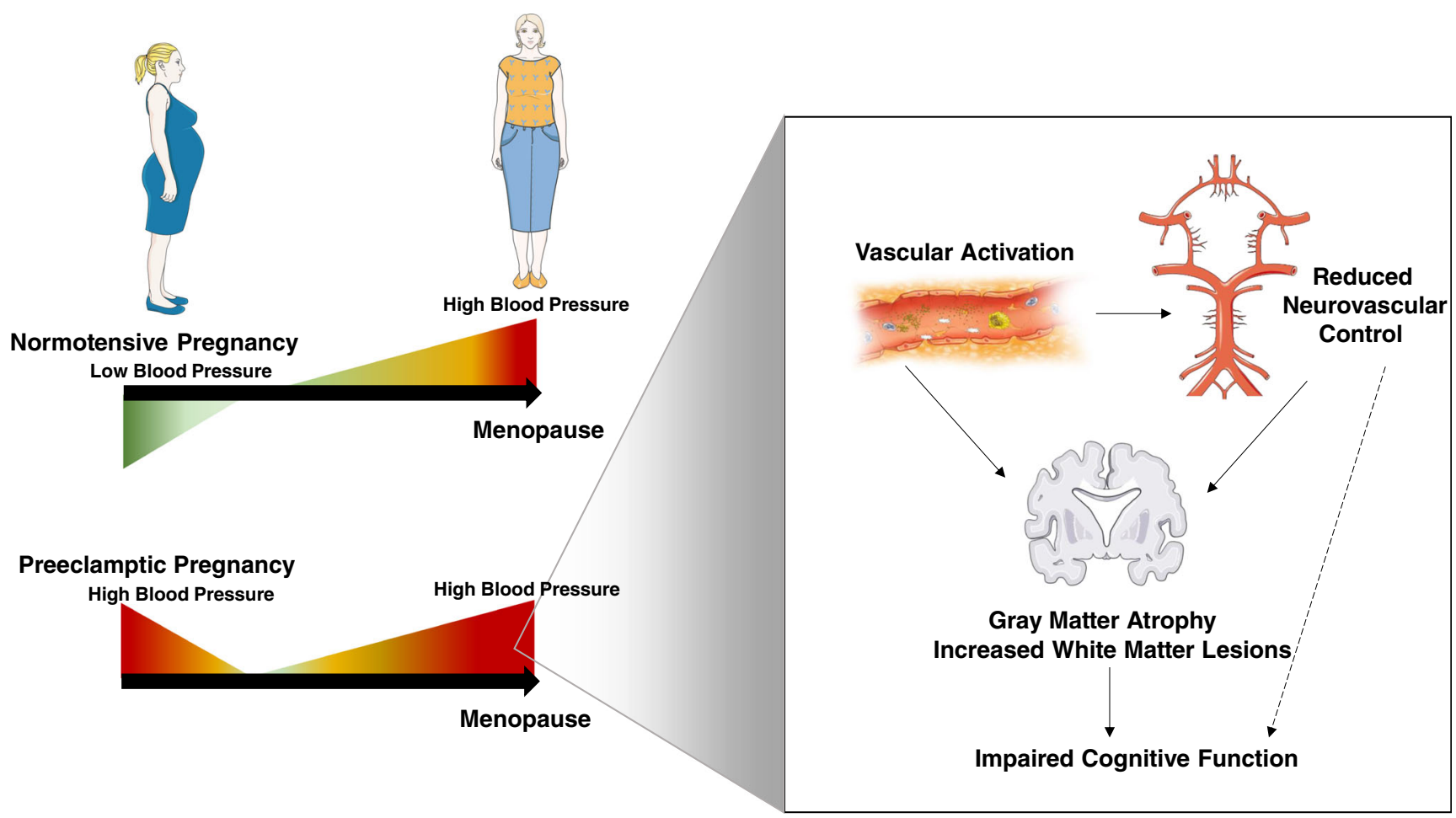

Fig. 1 Schematic summarizing studies of postmenopausal women with a history of preeclampsia. During normal pregnancy, blood pressure is reduced (green). However, during a preeclamptic pregnancy, blood pressure is elevated (red) after 20-week gestation, continues to be elevated throughout the pregnancy, and decreases back to prepregnancy levels after delivery. Aging and menopause increase risk for hypertension in women, and a history of preeclampsia augments hypertension risk. Postmenopausal women with a history of preeclampsia had impairments in neurovascular control that were associated with increased vascular activation compared with women who had a history of a normotensive pregnancy $[68 \bullet \bullet$. Gray matter atrophy in the occipital lobes were also observed in women with a history of preeclampsia and current controlled hypertension [73••] as were increased volume of white matter lesions as early as $<10$ years postpartum [71]. Brain structural changes were consistent with deficits in visual memory, as well as a trend for increased incidence of clinical cognitive impairment diagnosis with a more diffuse range (i.e., multiple domains) in cognitive impairment [74••]. We hypothesize that reduced neurovascular control is a potential mechanism by which a history of a preeclamptic pregnancy may augment risk for cognitive decline later in life. It is unclear at this time whether, when, and how reduced neurovascular control may progress in women with a history of a normotensive pregnancy as they age. It was also unclear whether the changes in the occipital cortex observed in hypertensive women with a history of preeclampsia are specific to that complication of pregnancy. This figure was created in part with modified Servier Medical Art templates, which are licensed under a Creative Commons Attribution 3.0 Unported License: https://smart.servier.com 
elevates cardiovascular risk, monitoring blood pressure in women with histories of preeclampsia after pregnancy and around perimenopause is essential. A simple validated questionnaire to inquire about the pregnancy history of women, if unknown, could be useful in clinical or research environments to help establish this potential risk [80]. In addition, studies and clinical trials aimed at attempting to assess the effect of blood pressure control on risk for Alzheimer's disease and other dementias should consider how their results are impacted by hormonal changes experienced by women throughout the life span (i.e., pregnancy and menopause) before making generalized conclusions about the effectiveness of the trials $[81,82]$.

In summary, study of a defined cohort of postmenopausal women who had a history of either a preeclamptic or normotensive pregnancy has provided insights into the associations of hypertension, central artery structure and functional changes, cerebrovascular function, brain structure, and cognition. These results can generate hypotheses for other longitudinal studies that will help to identify mechanisms by which changes in the hormonal milieu contribute to cerebrovascular aging, brain structure, and ultimately cognition.

\section{Compliance with Ethical Standards}

Conflict of Interest The authors declare financial support for their work from the National Institutes of Health P50 AG441170, HL118154, and HL007936.

Human and Animal Rights and Informed Consent All reported studies/ experiments with humans or animals performed by the authors have been previously published and complied with all applicable ethical standards (including the Helsinki declaration and its amendments, institutional/ national research committee standards, and international/national/institutional guidelines).

Open Access This article is distributed under the terms of the Creative Commons Attribution 4.0 International License (http:// creativecommons.org/licenses/by/4.0/), which permits unrestricted use, distribution, and reproduction in any medium, provided you give appropriate credit to the original author(s) and the source, provide a link to the Creative Commons license, and indicate if changes were made.

\section{References}

Papers of particular interest, published recently, have been highlighted as:

- Of importance

•. Of major importance

1. Skoog I, Lernfelt B, Landahl S, Palmertz B, Andreasson LA, Nilsson L, et al. 15-year longitudinal study of blood pressure and dementia. Lancet. 1996;347(9009):1141-5.
2. Launer LJ, Ross GW, Petrovitch H, Masaki K, Foley D, White LR, et al. Midlife blood pressure and dementia: the Honolulu-Asia aging study. Neurobiol Aging. 2000;21(1):49-55.

3. McNeil CJ, Myint PK, Sandu AL, Potter JF, Staff R, Whalley LJ, et al. Increased diastolic blood pressure is associated with MRI biomarkers of dementia-related brain pathology in normative ageing. Age Ageing. 2018;47(1):95-100.

4. Stone MC. Hypertension. The influence of age, sex and other risk factors. J R Coll Gen Pract Occas Pap. 1980;12:6-10.

5. Benjamin EJ, Muntner P, Alonso A, Bittencourt MS, Callaway CW, Carson AP, et al. Heart disease and stroke statistics - 2019 update: a report from the American Heart Association. Circulation. 2019;139(10):e56-e528.

6. Dufouil C, Seshadri S, Chene G. Cardiovascular risk profile in women and dementia. J Alzheimers Dis. 2014;42(Suppl 4):S35363.

7.• Rocca WA, Gazzuola Rocca L, Smith CY, Grossardt BR, Faubion SS, Shuster LT, et al. Loss of ovarian hormones and accelerated somatic and mental aging. Physiology (Bethesda). 2018;33(6): 374-83 Review of multimorbidities associated with bilateral oophorectomy prior to the age of natural menopause in women.

8. Garovic VD, August P. Preeclampsia and the future risk of hypertension: the pregnant evidence. Curr Hypertens Rep. 2013;15(2): 114-21.

9. Mannisto T, Mendola P, Vaarasmaki M, Jarvelin MR, Hartikainen $\mathrm{AL}$, Pouta A, et al. Elevated blood pressure in pregnancy and subsequent chronic disease risk. Circulation. 2013;127(6):681-90.

10. Gorelick PB, Scuteri A, Black SE, Decarli C, Greenberg SM, Iadecola $C$, et al. Vascular contributions to cognitive impairment and dementia: a statement for healthcare professionals from the American Heart Association/American Stroke Association. Stroke. 2011;42(9):2672-713.

11.• Iadecola C, Yaffe K, Biller J, Bratzke LC, Faraci FM, Gorelick PB, et al. Impact of hypertension on cognitive function: a scientific statement from the American Heart Association. Hypertension. 2016;68(6):e67-94 Good general review of the potential mechanisms and impact of hypertension on cognitive function. Only slight mention of potential sex differences as the general data on the topic are not robust.

12. Spieth W. Cardiovascular health status, age, and psychological performance. J Gerontol. 1964;19:277-84.

13. Wilkie F, Eisdorfer C. Intelligence and blood pressure in the aged. Science. 1971;172(3986):959-62.

14. Walker KA, Power MC, Gottesman RF. Defining the relationship between hypertension, cognitive decline, and dementia: a review. Curr Hypertens Rep. 2017;19(3):24.

15. Firbank MJ, Wiseman RM, Burton EJ, Saxby BK, O'Brien JT, Ford GA. Brain atrophy and white matter hyperintensity change in older adults and relationship to blood pressure. Brain atrophy, WMH change and blood pressure. J Neurol. 2007;254(6):713-21.

16. Raz N, Lindenberger U, Rodrigue KM, Kennedy KM, Head D, Williamson A, et al. Regional brain changes in aging healthy adults: general trends, individual differences and modifiers. Cereb Cortex. 2005;15(11):1676-89.

17. Jennings JR, Muldoon MF, Ryan C, Price JC, Greer P, SuttonTyrrell K, et al. Reduced cerebral blood flow response and compensation among patients with untreated hypertension. Neurology. 2005;64(8):1358-65.

18. Muller M, van der Graaf Y, Visseren FL, Mali WP, Geerlings MI, Group SS. Hypertension and longitudinal changes in cerebral blood flow: the SMART-MR study. Ann Neurol. 2012;71(6):825-33.

19. Immink RV, van den Born BJ, van Montfrans GA, Koopmans RP, Karemaker JM, van Lieshout JJ. Impaired cerebral autoregulation in patients with malignant hypertension. Circulation. 2004;110(15):2241-5. 
20. Langbaum JB, Chen K, Launer LJ, Fleisher AS, Lee W, Liu X, et al. Blood pressure is associated with higher brain amyloid burden and lower glucose metabolism in healthy late middle-age persons. Neurobiol Aging. 2012;33(4):827 e11-9.

21. Ashby EL, Miners JS, Kehoe PG, Love S. Effects of hypertension and anti-hypertensive treatment on amyloid-beta (Abeta) plaque load and Abeta-synthesizing and Abeta-degrading enzymes in frontal cortex. J Alzheimers Dis. 2016;50(4):1191-203.

22. Petrovitch H, White LR, Izmirilian G, Ross GW, Havlik RJ, Markesbery W, et al. Midlife blood pressure and neuritic plaques, neurofibrillary tangles, and brain weight at death: the HAAS. Honolulu-Asia aging study. Neurobiol Aging. 2000;21(1):57-62.

23. Iadecola $\mathrm{C}$. Neurovascular regulation in the normal brain and in Alzheimer's disease. Nat Rev Neurosci. 2004;5(5):347-60.

24. Kisler K, Nelson AR, Montagne A, Zlokovic BV. Cerebral blood flow regulation and neurovascular dysfunction in Alzheimer disease. Nat Rev Neurosci. 2017;18(7):419-34.

25. Rouch L, Cestac P, Hanon O, Cool C, Helmer C, Bouhanick B, et al. Antihypertensive drugs, prevention of cognitive decline and dementia: a systematic review of observational studies, randomized controlled trials and meta-analyses, with discussion of potential mechanisms. CNS Drugs. 2015;29(2):113-30.

26. Group SMIftSR, Williamson JD, Pajewski NM, Auchus AP, Bryan RN, Chelune G, et al. Effect of intensive vs standard blood pressure control on probable dementia: a randomized clinical trial. JAMA. 2019;321(6):553-61.

27. ACOG Practice Bulletin No. 202: gestational hypertension and preeclampsia. Obstet Gynecol. 2019;133(1):e1-e25.

28. Tranquilli AL, Dekker G, Magee L, Roberts J, Sibai BM, Steyn W, et al. The classification, diagnosis and management of the hypertensive disorders of pregnancy: a revised statement from the ISSHP. Pregnancy Hypertens. 2014;4(2):97-104.

29. Backes CH, Markham K, Moorehead P, Cordero L, Nankervis CA, Giannone PJ. Maternal preeclampsia and neonatal outcomes. J Pregnancy. 2011;2011:214365.

30. Duley L. The global impact of pre-eclampsia and eclampsia. Semin Perinatol. 2009;33(3):130-7.

31. Mosca L, Benjamin EJ, Berra K, Bezanson JL, Dolor RJ, LloydJones DM, et al. Effectiveness-based guidelines for the prevention of cardiovascular disease in women-2011 update: a guideline from the American Heart Association. Circulation. 2011;123(11): $1243-62$.

32. Kristensen JH, Basit S, Wohlfahrt J, Damholt MB, Boyd HA. Preeclampsia and risk of later kidney disease: nationwide cohort study. BMJ. 2019;365:11516.

33. Meekins JW, Pijnenborg R, Hanssens M, McFadyen IR, van Asshe A. A study of placental bed spiral arteries and trophoblast invasion in normal and severe pre-eclamptic pregnancies. Br J Obstet Gynaecol. 1994;101(8):669-74.

34. Roberts JM, Redman CW. Pre-eclampsia: more than pregnancyinduced hypertension. Lancet. 1993;341(8858):1447-51.

35. Phipps E, Prasanna D, Brima W, Jim B. Preeclampsia: updates in pathogenesis, definitions, and guidelines. Clin J Am Soc Nephrol. 2016;11(6):1102-13.

36. Myatt L, Webster RP. Vascular biology of preeclampsia. J Thromb Haemost. 2009;7(3):375-84.

37. Maynard SE, Karumanchi SA. Angiogenic factors and preeclampsia. Semin Nephrol. 2011;31(1):33-46.

38. Myatt L. Role of placenta in preeclampsia. Endocrine. 2002;19(1): 103-11.

39. Greenwood JP, Scott EM, Walker JJ, Stoker JB, Mary DA. The magnitude of sympathetic hyperactivity in pregnancy-induced hypertension and preeclampsia. Am J Hypertens. 2003;16(3):194-9.

40. Schobel HP, Fischer T, Heuszer K, Geiger H, Schmieder RE. Preeclampsia - a state of sympathetic overactivity. N Engl J Med. 1996;335(20):1480-5.
41. Bartsch E, Medcalf KE, Park AL, Ray JG. High Risk of Preeclampsia Identification G. Clinical risk factors for pre-eclampsia determined in early pregnancy: systematic review and metaanalysis of large cohort studies. BMJ. 2016;353:i1753.

42. Sibai BM, el-Nazer A, Gonzalez-Ruiz A. Severe preeclampsiaeclampsia in young primigravid women: subsequent pregnancy outcome and remote prognosis. Am J Obstet Gynecol. 1986;155(5):1011-6.

43. van Rijn BB, Hoeks LB, Bots ML, Franx A, Bruinse HW. Outcomes of subsequent pregnancy after first pregnancy with early-onset preeclampsia. Am J Obstet Gynecol. 2006;195(3): $723-8$.

44. Riise HKR, Sulo G, Tell GS, Igland J, Nygard O, Iversen AC, et al. Association between gestational hypertension and risk of cardiovascular disease among 617589 Norwegian women. J Am Heart Assoc. 2018;7(10):1-10.

45.• Basit S, Wohlfahrt J, Boyd HA. Pre-eclampsia and risk of dementia later in life: nationwide cohort study. BMJ. 2018;363:k4109 This study found that in a large cohort, women with a history of preeclampsia had three times the risk for vascular dementia compared to women with no history of preeclampsia. The authors highlighted the importance of screening women based on pregnancy history for early signs of disease to allow for early clinical intervention.

46.• White WM, Mielke MM, Araoz PA, Lahr BD, Bailey KR, Jayachandran $\mathrm{M}$, et al. A history of preeclampsia is associated with a risk for coronary artery calcification 3 decades later. Am J Obstet Gynecol. 2016;214(4):519 e1-8 This study showed that postmenopausal women with a history of preeclampsia had an increased risk for coronary artery calcification (CAC) over 30 years later. The presence of CAC could identify women with a history of preeclampsia that are at higher cardiovascular risk.

47.• Garovic VD, Milic NM, Weissgerber TL, Mielke MM, Bailey KR, Lahr B, et al. Carotid artery intima-media thickness and subclinical atherosclerosis in women with remote histories of preeclampsia: results from a Rochester Epidemiology Project-Based Study and Metaanalysis. Mayo Clin Proc. 2017;92(9):1328-40 This study found that postmenopausal women with a history of preeclampsia demonstrated elevated carotid artery intima-media thickness compared with women who had a history of a normotensive pregnancy, suggesting subclinical atherosclerosis.

48. Nichols WW, O'Rourke MF. McDonalds's blood flow in arteries: theoretical, experimental and clinical principles. 5th ed. London: Hodder Arnold Publishing; 2005.

49. Kollias A, Lagou S, Zeniodi ME, Boubouchairopoulou N, Stergiou GS. Association of central versus brachial blood pressure with target-organ damage: systematic review and meta-analysis. Hypertension. 2016;67(1):183-90.

50. Yoshita M, Fletcher E, Harvey D, Ortega M, Martinez O, Mungas $\mathrm{DM}$, et al. Extent and distribution of white matter hyperintensities in normal aging, MCI, and AD. Neurology. 2006;67(12):2192-8.

51. Silbert LC, Nelson C, Howieson DB, Moore MM, Kaye JA. Impact of white matter hyperintensity volume progression on rate of $\operatorname{cog}$ nitive and motor decline. Neurology. 2008;71(2):108-13.

52. Barnes JN, Harvey RE, Zuk SM, Lundt ES, Lesnick TG, Gunter JL, et al. Aortic hemodynamics and white matter hyperintensities in normotensive postmenopausal women. J Neurol. 2017;264(5): 938-45.

53. Oylumlu M, Oylumlu M, Yuksel M, Yildiz A, Bilik MZ, Akil MA, et al. A simple method for the assessment of arterial stiffness in preeclamptic patients. Clin Exp Hypertens. 2014;36(8):531-7.

54. Franz MB, Burgmann M, Neubauer A, Zeisler H, Sanani R, Gottsauner-Wolf M, et al. Augmentation index and pulse wave velocity in normotensive and pre-eclamptic pregnancies. Acta Obstet Gynecol Scand. 2013;92(8):960-6. 
55. Robb AO, Mills NL, Din JN, Smith IB, Paterson F, Newby DE, et al. Influence of the menstrual cycle, pregnancy, and preeclampsia on arterial stiffness. Hypertension. 2009;53(6):952-8.

56. Cipolla MJ, DeLance N, Vitullo L. Pregnancy prevents hypertensive remodeling of cerebral arteries: a potential role in the development of eclampsia. Hypertension. 2006;47(3):619-26.

57. Johnson AC, Cipolla MJ. Altered hippocampal arteriole structure and function in a rat model of preeclampsia: potential role in impaired seizure-induced hyperemia. J Cereb Blood Flow Metab. 2017;37(8):2857-69.

58. Ryan MJ, Gilbert EL, Glover PH, George EM, Masterson CW, McLemore GR Jr, et al. Placental ischemia impairs middle cerebral artery myogenic responses in the pregnant rat. Hypertension. 2011;58(6):1126-31.

59.• Johnson AC, Cipolla MJ. Impaired function of cerebral parenchymal arterioles in experimental preeclampsia. Microvasc Res. 2018;119:64-72 This study found that cerebral parenchymal arteriole function was impaired in an experimental model of preeclampsia. These findings provide insights into the mechanisms by which cerebrovascular dysfunction may impact cognition in women with a history of preeclampsia.

60. Hammer ES, Cipolla MJ. Cerebrovascular dysfunction in preeclamptic pregnancies. Curr Hypertens Rep. 2015;17(8):64 Comprehensive overview of the cerebrovascular dysfunction in preeclampsia and how this may lead to changes in brain structure, cognitive function, and clinical outcomes.

61. Cipolla MJ, Sweet JG, Chan SL. Cerebral vascular adaptation to pregnancy and its role in the neurological complications of eclampsia. J Appl Physiol (1985). 2011;110(2):329-39.

62. Xie A, Skatrud JB, Morgan B, Chenuel B, Khayat R, Reichmuth K, et al. Influence of cerebrovascular function on the hypercapnic ventilatory response in healthy humans. J Physiol. 2006;577(Pt 1):319 29.

63. Galvin SD, Celi LA, Thomas KN, Clendon TR, Galvin IE, Bunton $\mathrm{RW}$, et al. Effects of age and coronary artery disease on cerebrovascular reactivity to carbon dioxide in humans. Anaesth Intensive Care. 2010;38(4):710-7.

64. Glodzik L, Randall C, Rusinek H, de Leon MJ. Cerebrovascular reactivity to carbon dioxide in Alzheimer's disease. J Alzheimers Dis. 2013;35(3):427-40.

65. Riecker A, Grodd W, Klose U, Schulz JB, Groschel K, Erb M, et al. Relation between regional functional MRI activation and vascular reactivity to carbon dioxide during normal aging. J Cereb Blood Flow Metab. 2003;23(5):565-73.

66. Riskin-Mashiah S, Belfort MA, Saade GR, Herd JA. Cerebrovascular reactivity in normal pregnancy and preeclampsia. Obstet Gynecol. 2001;98(5 Pt 1):827-32.

67. Sariri E, Vahdat M, Behbahani AS, Rohani M, Kashanian M. Cerebro vascular reactivity (CVR) of middle cerebral artery in response to $\mathrm{CO} 25 \%$ inhalation in preeclamptic women. J Matern Fetal Neonatal Med. 2013;26(10):1020-3.

68.• Barnes JN, Harvey RE, Miller KB, Jayachandran M, Malterer KR, Lahr BD, et al. Cerebrovascular reactivity and vascular activation in postmenopausal women with histories of preeclampsia. Hypertension. 2018;71(1):110-7 This study found that postmenopausal women with a history of preeclampsia demonstrated a reduced cerebral blood velocity response to a vasodilatory stimulus, which was associated with vascular activation. This suggests that a preeclamptic pregnancy history is associated with impairments in cerebrovascular function 35 years postpartum.

69. Aukes AM, de Groot JC, Aarnoudse JG, Zeeman GG. Brain lesions several years after eclampsia. Am J Obstet Gynecol. 2009;200(5): 504 e1-5.
70. Aukes AM, De Groot JC, Wiegman MJ, Aarnoudse JG, Sanwikarja GS, Zeeman GG. Long-term cerebral imaging after pre-eclampsia. BJOG. 2012;119(9):1117-22.

71. Wiegman MJ, Zeeman GG, Aukes AM, Bolte AC, Faas MM, Aarnoudse JG, et al. Regional distribution of cerebral white matter lesions years after preeclampsia and eclampsia. Obstet Gynecol. 2014;123(4):790-5.

72. Mielke MM, Milic NM, Weissgerber TL, White WM, Kantarci K, Mosley $\mathrm{TH}$, et al. Impaired cognition and brain atrophy decades after hypertensive pregnancy disorders. Circ Cardiovasc Qual Outcomes. 2016;9(2 Suppl 1):S70-6.

73.• Raman MR, Tosakulwong N, Zuk SM, Senjem ML, White WM, Fields JA, et al. Influence of preeclampsia and late-life hypertension on MRI measures of cortical atrophy. J Hypertens. 2017;35(12): 2479-85 This study found that gray matter volume was reduced in postmenopausal women with a history of preeclampsia and current hypertension. Furthermore, a voxel-based analysis identified regional atrophy, suggesting that pregnancy history and hypertension also affect gray matter structure regionally.

74.• Fields JA, Garovic VD, Mielke MM, Kantarci K, Jayachandran M, White WM, et al. Preeclampsia and cognitive impairment later in life. Am J Obstet Gynecol. 2017;217(1):74 e1-e11 This study found that in postmenopausal women, there was a trend for those with a history of preeclampsia to be diagnosed with clinical cognitive impairment. Furthermore, cognitive impairment in women with a history of preeclampsia was more diffuse.

75. Postma IR, Bouma A, Ankersmit IF, Zeeman GG. Neurocognitive functioning following preeclampsia and eclampsia: a long-term follow-up study. Am J Obstet Gynecol. 2014;211(1):37 e1-9.

76. Roes EM, Raijmakers MT, Schoonenberg M, Wanner N, Peters WH, Steegers EA. Physical well-being in women with a history of severe preeclampsia. J Matern Fetal Neonatal Med. 2005;18(1):39-45.

77. Baecke M, Spaanderman ME, van der Werf SP. Cognitive function after pre-eclampsia: an explorative study. J Psychosom Obstet Gynaecol. 2009;30(1):58-64.

78. Brusse I, Duvekot J, Jongerling J, Steegers E, De Koning I. Impaired maternal cognitive functioning after pregnancies complicated by severe pre-eclampsia: a pilot case-control study. Acta Obstet Gynecol Scand. 2008;87(4):408-12.

79. Whelton PK, Carey RM, Aronow WS, Casey DE Jr, Collins KJ, Dennison Himmelfarb C, et al. 2017 ACC/AHA/AAPA/ABC/ ACPM/AGS/APhA/ASH/ASPC/NMA/PCNA guideline for the prevention, detection, evaluation, and management of high blood pressure in adults: executive summary: a report of the American College of Cardiology/American Heart Association Task Force on Clinical Practice Guidelines. Circulation. 2018;138(17):e426-e83.

80. Diehl CL, Brost BC, Hogan MC, Elesber AA, Offord KP, Turner ST, et al. Preeclampsia as a risk factor for cardiovascular disease later in life: validation of a preeclampsia questionnaire. Am J Obstet Gynecol. 2008;198(5):e11-3.

81. Yasar S, Schuchman M, Peters J, Anstey KJ, Carlson MC, Peters R. Relationship between antihypertensive medications and cognitive impairment: part I. Review of human studies and clinical trials. Curr Hypertens Rep. 2016;18(8):67.

82. Nebel RA, Aggarwal NT, Barnes LL, Gallagher A, Goldstein JM, Kantarci K, et al. Understanding the impact of sex and gender in Alzheimer's disease: a call to action. Alzheimers Dement. 2018;14(9):1171-83.

Publisher's Note Springer Nature remains neutral with regard to jurisdictional claims in published maps and institutional affiliations. 